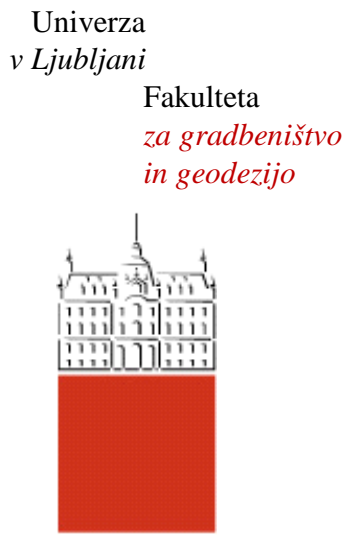

Jamova 2

1000 Ljubljana, Slovenija http://www3.fgg.uni-lj.si/

DRUGG - Digitalni repozitorij UL FGG http://drugg.fgg.uni-lj.si/

Ta članek je avtorjeva zadnja recenzirana različica, kot je bila sprejeta po opravljeni recenziji.

Prosimo, da se pri navajanju sklicujete na bibliografske podatke, kot je navedeno:

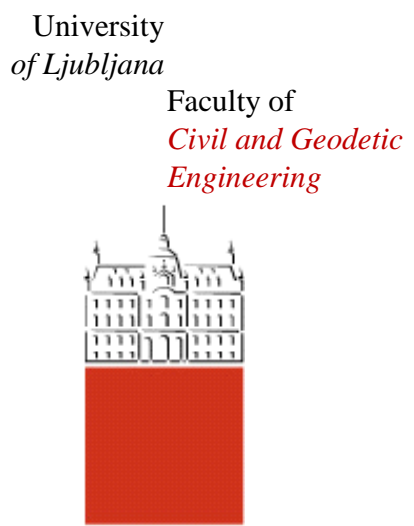

Jamova 2

SI - 1000 Ljubljana, Slovenia http://www3.fgg.uni-lj.si/en/

DRUGG - The Digital Repository http://drugg.fgg.uni-lj.si/

This version of the article is author's manuscript as accepted for publishing after the review process.

When citing, please refer to the publisher's bibliographic information as follows:

Trtnik, G., Turk, G., Kavčič, F. in Bokan Bosiljkov, V. 2008. Possibilities of using the ultrasonic wave transmission method to estimate initial setting time of cement paste. Cement and Concrete Research 38, 11: 1336-1342.

DOI: 10.1016/j.cemconres.2008.08.003. 


\title{
Possibilities of using the ultrasonic wave transmission method to estimate initial setting time of cement paste
}

\author{
Gregor Trtnik $^{\mathrm{a}, \mathrm{b}}$, Goran Turk ${ }^{\mathrm{a}}$, Franci Kavčič ${ }^{\mathrm{b}}$, Violeta Bokan Bosiljkov ${ }^{\mathrm{a}, *}$ \\ ${ }^{a}$ University of Ljubljana, Faculty of Civil and Geodetic Engineering \\ Jamova 2, SI-1115 Ljubljana, Slovenia \\ ${ }^{\mathrm{b}}$ IGMAT d.d., Building Materials Institute, Polje 351c, Ljubljana, Slovenia
}

\begin{abstract}
In this paper, the applicability of the ultrasonic wave transmission method to estimate the initial setting time of an arbitrary cement paste is discussed. Ultrasonic pulse velocity measurements were fully automated and measured continuously. The Vicat Needle Test was used in order to determine the initial setting time of cement pastes. Different cement pastes were prepared in order to check the influence of the water/cement ratio, type of cement, curing temperature, cement fineness, and some clinker compositions, on the relationship between the initial setting time and ultrasonic pulse velocity. It was found that the initial setting time of an arbitrary cement paste can be estimated very accurately by the time the first inflection point appears on the ultrasonic pulse velocity curve. Moreover, it can be estimated quite accurately by the time the ultrasonic pulse velocity reaches a fixed value, close to the value of the ultrasonic pulse velocity in water.
\end{abstract}

Keywords: Hydration (A); Cement paste (D); No category: Ultrasonic wave transmission, Initial setting time

\footnotetext{
${ }^{*}$ Corresponding author. Phone: +38614768663

E-mail address: violeta.bokan-bosiljkov@fgg.uni-lj.si
} 


\section{Introduction}

Many test methods which evaluate the change of properties of cement-based materials with time exist. These methods have different ranges of applicable material properties. Therefore, they are applicable to different time-ranges in the setting and hardening processes of cement.

With the Vicat Needle [1] and Proctor Penetration Resistance [2] tests, the setting and hardening states of the materials in the early stages are investigated by means of the change in the materials' penetration resistance. Unfortunately, these procedures do not allow measuring of setting and hardening processes continuously, or are not based on truly mechanical parameters of the test material.

Advances in measurement and computer technologies in recent years have allowed the development of many advanced methods to monitor the setting and hardening process of cement paste, such as impactecho methods, pulse-echo methods, ultrasonic pulse velocity methods, wave reflection methods, resonant frequency methods, acoustic emission methods, microwave adsorption methods, techniques measuring the conductivity and resistance of the material to be tested, and so on. Some of these are completely nondestructive in their nature, which is another advantage of these methods over classical standard methods, mentioned above.

Numerous attempts have been made during the last few years to determine some properties of hardening cement-based materials with different ultrasonic methods. Valič [3] presented a new apparatus, method, and some application examples for monitoring the hydration process of cementitious materials, by the pulse echo ultrasonic wave reflection method. Reinhardt et al. $[4,5]$ evaluated changes in the material properties associated with concrete aging by using the velocity of elastic waves, energy, and frequency distribution of obtained waves. The ultrasonic wave transmission method was used in these studies.

A comparison between ultrasonic wave transmission and reflection measurements, using primary waves (P - waves) and secondary waves (S- waves) on mortar and concrete, in the early stages, was made by Voight et al. [6].

Kamada et al. [7] presented the relationship between ultrasonic propagation characteristics and some properties of hardening cement paste and Krauss and Hariri [8] presented a procedure to determine the end of the dormant phase and initial degree of hydration by measuring the ultrasonic pulse velocities of compression and shear waves for arbitrary concrete compositions. Also, numerous attempts were made to 
investigate the microstructure of cement-based materials by ultrasonic shear waves and numerical simulation $[9,10,11]$ and some other properties of fresh cement-based materials $[12,13]$.

Researchers have also suggested some methods based on ultrasonic wave transmission measurements for identifying characteristic times in the hydration of cement. According to Chotard et al. [14], important transition points in the ultrasonic pulse velocity (UPV) curve can be determined at the intersections of three straight lines tangent to the curve.

In some other studies it was shown that the maximum of the first derivative of the UPV curves is a practical means to determine the initial setting of mortars and concretes $[4,5,6]$, while the final setting cannot clearly be associated with typical curve values, but it was suggested to choose the time when a velocity value of $1500 \mathrm{~m} / \mathrm{s}$ on the concrete's UPV curve is exceeded.

According to Lee et al. [15], certain ranges of ultrasonic pulse velocity values $(\mathrm{Vp})$ with reasonable widths were suggested for the initial setting times: i.e., $800-900 \mathrm{~m} / \mathrm{s}$ and $920-1070 \mathrm{~m} / \mathrm{s}$ for the initial setting of ordinary Portland cement concrete and high-performance concrete, respectively.

The objective of this study was to investigate the relationship between the initial setting time (IST) of cement paste and ultrasonic propagation characteristics. Therefore, a comprehensive experimental work was performed in which the ultrasonic wave transmission method was used. The influence of the water/cement $(\mathrm{w} / \mathrm{c})$ ratio, environmental temperature $(\mathrm{T})$, type of cement $(\mathrm{CT})$, cement fineness $(\mathrm{BS})$, and amount of $\mathrm{C}_{3} \mathrm{~A}(\mathrm{AC} 3 \mathrm{~A})$ on the initial setting time of cement paste, determined from UPV curves and Vicat Needle tests, was studied.

\section{Experimental methods}

\subsection{Wave transmission method}

The Proceq CCT4 set up was chosen as the foundation and was adequately augmented to measure the $V p$ automatically at any desired intervals after casting. This fully automated determination of the initial onset of the signal is of special significance to routine industrial application. The apparatus was connected to the PC computer and special software was prepared in order to collect $V p$ data with time. The travel time of the ultrasonic pulse $t_{p}(\mu \mathrm{s})$ through the sample is measured and the $V p(\mathrm{~km} / \mathrm{s})$ is calculated as follows: 


$$
V p=\frac{L}{t_{p}}
$$

where $L(\mathrm{~mm})$ is the length of the straight-wave-path through the specimen (i.e. $70 \mathrm{~mm}$ in this study). Cubic specimens of the size of $80 \times 80 \times 80 \mathrm{~mm}^{3}$ were used in the study. The apparatus consists of a waveform generator board and two broadband transducers of central frequency $54 \mathrm{kHz}$ and $25 \mathrm{~mm}$ in diameter. With regards to the apparatus technology, one of the focal tasks has been the development of an easily manageable container.

After several tests, it was decided to make the container of the extruded polystyrene foam Styrodur. It is important to mention that no waves propagating through the container wall were detected by the device because of the high dissipation of the Styrodur material. This is of significant importance, specifically for carrying out measurements on very fresh cement-based materials. The sensors were partly pushed into the specimens (about $5 \mathrm{~mm}$ ) in order to ensure good contact between transducers and specimen and the acoustic coupling was enhanced by a layer of roller bearing grease, which has been found more appropriate than other commercial ultrasonic couplings. The $V p$ measurements started immediately after casting and continued for 36 hours. The results were recorded at one minute intervals in order to capture all important trends of the UPV development.

\subsection{Vicat test of penetration resistance}

To evaluate the progress of the hydration reaction of the investigated materials, Vicat Needle tests (VNT) according to [1] were conducted. The method is based on measuring a depth of penetration of a steel right cylinder needle into the cement paste. The time between starting time and the time at which the distance between the needle and the base plate is $d=6 \pm 3 \mathrm{~mm}$, measured to the nearest minute, is defined as the initial setting time (IST) of the cement.

Within this study, penetration tests were performed at regular time intervals until the cement paste was completely set. 


\section{Experimental program}

\subsection{Materials}

Twelve cement pastes were prepared in order to achieve the objective of this study. Four types of Portland cements, which are presented in Table 1, were used. In Table 1, AC stands for the clinker content in each cement.

Table 1

The calculated Bogue compositions of these cements (mass fractions) were deduced from the chemical characterization (Table 1). In order to get three different values of cement fineness, cement types $\mathrm{C} 2$ and C3 were used separately and one mixture (namely MF3, see Table 2) was prepared by mixing these two cements in a ratio of 50/50. This can be done because of very similar chemical composition of these cements. A similar procedure was used in order to obtain three values of $\mathrm{C}_{3} \mathrm{~A}$. Cement types $\mathrm{C} 3$ and $\mathrm{C} 4$ were used for this purpose (see Table 2).

Table 2

\subsection{Reproducibility}

In order to check the reproducibility of the methods, the tests on mixture MC1035 were repeated 3 times before some other mixtures were tested. Fig. $1 \mathrm{a}$ and $1 \mathrm{~b}$ present the results, measured by the wave transmission method and the Vicat Needle test, respectively. The inherent scattering in this test was very small and the equipment's reproducibility very high. This statement turned out to be valid for most other experiments conducted using the device described.

Fig. 1. 


\section{Experimental results}

\subsection{General evolution of $V p$}

Fig. $2 \mathrm{a}$ and $2 \mathrm{~b}$ show a typical UPV curve and the first derivative of the UPV curve during the first 24 hours for the cement paste mixture, obtained by our experiments, respectively. Some researchers divide the evolution of $V p$ of different cement-based materials into three stages $[5,7,11,15]$. However, within this study, four stages are defined (see Fig. 2a).

At stage 1, no $V p$ was observed. During this dormant induction period, ultrasonic waves propagate through the water-like viscous suspension.

After a certain time, usually between 20 and 60 minutes, depending on the $\mathrm{w} / \mathrm{c}$ ratio, $\mathrm{T}, \mathrm{CT}$, BS, and AC3A, ultrasonic waves could be obtained at any time [7]. The measured velocity of approximately 300 $\mathrm{m} / \mathrm{s}$ was observed at the beginning of stage 2 for all mixtures. This value is lower than the $V p$ in water $(1430 \mathrm{~m} / \mathrm{s})$ and air $(340 \mathrm{~m} / \mathrm{s})$. There exist two theories which explain this phenomenon. According to Rapoport et al. [16], this can be explained by the highly elongated length of the wave-path because of the suspended cement grains in fresh cement-based materials.

Fig. 2.

According to Keating [17] and Sayers [18], this phenomenon is caused by the air entrapped in the paste because of a certain amount of air bubbles in the mixing water, or a huge number of tiny air bubbles that are entrapped in the paste during mixing. Within the second stage, the wave velocity then increases gradually up to levels close to those found in water. After a certain time, depending on the w/c ratio, T, $\mathrm{CT}$, BS, and AC3A, the first inflection point IP1 appears near this value for all mixtures (see Fig. 2b). This point is defined as the end of stage 2 in this study. The increase of $V p$ can only be attributed to the formation of hydration products that have no, or very little, influence on the penetration resistance, measured by the Vicat Needle test. $V p$ is strongly affected by the formation of ettringite crystals at this stage. At stage 3, Vp gradually increases to approximately $3000 \mathrm{~m} / \mathrm{s}$, again depending on the $\mathrm{w} / \mathrm{c}$ ratio, $\mathrm{T}$, 
CT, BS, and AC3A. Within this stage, the second inflection point IP2 appears (see Fig. 2b). After that, the plateau is reached and only a small increase of $V p$ can be observed after the end of stage 3 .

This behaviour can be explained by a decrease in the volume of water and an increase in the amount of hydration products with the progress of cement hydration in the cement paste. A fully connected solid frame is formed [11]. This plateau is defined as stage 4 in this study.

\subsection{Influence of discussed parameters on the evolution of $V p$}

In Fig. 3, the influence of the discussed parameters on the evolution of $V p$ is briefly presented. Therefore, the sensitivity of the ultrasonic wave transmission method on the hydration and formation of structure of different cement pastes can be clearly observed from this Fig.

Fig. 3a shows the influence of the w/c ratio on the evolution of $V p$. As expected, mixtures with a higer w/c ratio show lower values of the ultrasonic pulse velocity, which can be related to the microstructure of the cement paste. The evolution of $V p$ was found to be in a close relationship with volume fraction of total and connected solid phase and it is well known that these two quantities are higher in the case of lower $\mathrm{w} / \mathrm{c}$ ratio $[11]$.

Fig. $3 \mathrm{~b}$ shows the influence of the cement type on the evolution of $V p$. It can be seen that cement type has a significant influence on the $V p$ evolution.

The influence of the environmental temperature on the evolution of $V p$ is shown in Fig 3c. It can be seen that the higher environmental temperature results in a more rapid evolution of $V p$ at the very beginning. After the plateau is reached, the temperature shows less influence on the ultrasonic pulse velocity. This is in good agreement with the results, obtained by Ye [11]. The influence of the cement fineness is shown in

Fig 3d. It can be seen that the cement fineness has an important influence on the evolution of $V p$, especially at the very beginning of the hydration process. As expected, higher fineness results in a more rapid hydration process [19] and consecutively to the more rapid evolution of $\mathrm{Vp}$.

Fig. 3e shows the influence of the amount of tri-calcium aluminate $\left(\mathrm{C}_{3} \mathrm{~A}\right)$ together with the influence of cement fineness. Even though cement type $\mathrm{C} 4$ has higher fineness than cement type $\mathrm{C} 3$ (see Table 1), it has a lower amount of $\mathrm{C}_{3} \mathrm{~A}$, which finally results in the slower evolution of $\mathrm{Vp}$. Therefore, it can be concluded that lower amount of $\mathrm{C}_{3} \mathrm{~A}$ results in a slightly slower evolution of $\mathrm{Vp}$. 
Fig. 3.

\section{Estimation of the initial setting time of cement pastes with the ultrasonic wave transmission method}

To achieve the objective of this study, the evolution of $V p$ was compared with the evolution of the penetration of the Vicat Needle test for each cement paste mixture, separately. According to [1], the initial setting time of cement is defined as the time when the distance $d$, between the needle and the base plate, is $6 \pm 3 \mathrm{~mm}$ (see Section 2.2). Therefore, the times when these distances were $3 \mathrm{~mm}$ and $9 \mathrm{~mm}$ were labelled as $t 3$ and $t 9$, respectively. Fig 4 shows the comparison between $V p$ and $d$ for each mixture.

Fig. 4.

Alternatively to times $t 3$ and $t 9$ determined by Vicat Needle test, the initial setting time, IST, is determined from the results of UPV measurements: $t_{I P 1}$ is defined as the time of the first inflection point on the UPV curve, whereas $t_{w}$ corresponds to the time when the ultrasonic pulse velocity reaches the ultrasonic pulse velocity in water $(1430 \mathrm{~m} / \mathrm{s})$.

In Fig. 5 the comparison between the interval $t 3-t 9$ and values $t_{I P 1}$ and $t_{w}$ for different values of w/c ratio, curing temperature, cement fineness, and type of cement is shown. A shadowed area indicates the interval between $t 3$ and $t 9$ values, determined with standard Vicat needle method. It is evident that the time interval between $t 3$ and $t 9$ values is narrow and that $t_{I P 1}$ and $t_{w}$ values correspond very well with the $t 3$ and t9 values.

Fig. 5.

It is well known, that the lower w/c ratio, higher curing temperature, and higher cement fineness, results in a shorter initial setting time [19]. These phenomena can be also observed from Fig 5a, Fig 5b, and Fig $5 \mathrm{c}$, respectively. 
The values of $V p$, which correspond to the times $t 3, t 9$, and $t_{I P 1}$ are denoted as $V p_{3}, V p_{9}$ and $V p_{I P 1}$ in this study, respectively. It can be seen from Table 3 that these values are very close to the value of $V p$ in water $(1430 \mathrm{~m} / \mathrm{s})$. Moreover, the values of $V p_{3}, V p_{9}$ and $V p_{I P 1}$ are quite similar for all cement paste mixtures. The average value of $V p_{3}$ was $V p_{3}{ }^{\prime}=1401.5 \mathrm{~m} / \mathrm{s}$, the average value of $V p_{9}$ was $V p_{9}{ }^{\prime}=1450.7 \mathrm{~m} / \mathrm{s}$, and the average value of $V p_{I P 1}$ was $V p_{I P 1^{\prime}}=1414.2 \mathrm{~m} / \mathrm{s}$.

Therefore, according to this study, the initial setting time of an arbitrary cement paste can be defined very accurately by the time when the first inflection point appears on the UPV curve. An alternative approach would be to define the initial setting time as the time when the $V p$ value reaches a value between 1400 $\mathrm{m} / \mathrm{s}$ and $1450 \mathrm{~m} / \mathrm{s}$, or the time when the value of $V p$ reaches the value of $V p$ in water, which occurs near the inflection point on an arbitrary UPV curve.

\section{Table 3}

\section{Conclusions}

The ability of the ultrasonic wave transmission method to estimate the initial setting time of different cement pastes was studied in this paper.

It was shown that the proposed wave transmission method can be used very effectively to monitor the hydration and formation of the structure of an arbitrary cement paste mixture.

For the discussed variable data set, the proposed wave transmission method appeared to be appropriate and effective for a quick and reliable estimation of the initial setting time of an arbitrary cement paste mixture. The initial setting time can be defined very accurately by the first inflection point on the ultrasonic pulse velocity curve. Alternatively, one can also estimate the initial setting time by the time when the ultrasonic pulse velocity of the longitudinal waves reaches a selected value within the suggested narrow interval, close to the value of the velocity of longitudinal ultrasonic waves in water. The latter estimate is slightly less accurate. This statement seems to be true for an arbitrary cement paste mixture. 
Therefore, according to this study, the estimation of the initial setting time of the cement paste with the ultrasonic wave transmission method is practical, reliable, and has a prospect of application in construction practice.

\section{Acknowledgements}

The work of G. Trtnik was financially supported by the Ministry of Education, Science and Sport, of the Republic of Slovenia, under contract 3211-05-000556. The support is gratefully acknowledged.

\section{References}

[1] EN 196-3:2005, Methods of testing cement - Part 3: Determination of setting times and soundness, April 2005.

[2] ASTM C 403-88, Standard test method for Time of Setting of Concrete Mixtures by Penetration Resistance, American society for testing and materials, 1988.

[3] M. I. Valič, Hydration of cementitious materials by pulse echo USWR - method, apparatus and application examples, Cement and Concrete Research 30 (10) (2000) 1633-1640.

[4] H. W. Reinhardt, C. U. Grosse, Continuous monitoring of setting and hardening of mortar and concrete, Construction and building materials 18 (3) (2004) 145-154.

[5] C. U. Grosse, H. W. Reinhardt, New developments in quality control of concrete using ultrasound, Non-Destructive Testing in Civil Engineering, International Symposium NDT-CE (2003).

[6] T. Voigt, C. U. Grosse, Z. Sun, S. P. Shah, H. W. Reinhardt, Comparison of ultrasonic wave transmission and reflection measurements with P- and S-waves on early age mortar and concrete, Materials and Structures 38 (2005) 729-738.

[7] T. Kamada, S. Uchida, K. Rokugo, Non-destructive evaluation of setting and hardening of cement paste based on ultrasonic propagation characteristics, Journal of Advanced Technology 3 (3) (2005) 343-353.

[8] M. Krauss, K. Hariri, Determination of initial degree of hydration for improvement of early-age properties of concrete using ultrasonic wave propagation, Cement and Concrete Composites 28 (4) (2006) 299-306. 
[9] T. Voigt, Z. Sun, S. P. Shah, Comparison of ultrasonic wave reflection method and maturity method in evaluating early-age compressive strength of mortar, Cement and Concrete Composites 28 (4) (2006) $307-316$.

[10] T. Voigt, G. Ye, Z. Sun, S. P. Shah, K. Van Breugel, Early age microstructure of Portland cement mortar investigated by ultrasonic shear waves and numerical simulation, Cement and Concrete Research 35 (5) (2005) 858-866.

[11] G. Ye, Experimental study and numerical simulation of the development of microstructure and permeability of cementitious materials, PhD Theses, Delft, 2003.

[12] Z. Sun, T. Voight, S. P. Shah, Rheometric and ultrasonic investigations of viscoelastic properties of fresh Portland cement pastes, Cement and Concrete Research 36 (2) (2006) 278-287.

[13] T. Voigt, T. Malonn, S. P. Shah, Green and early age compressive strength of extruded cement mortar monitored with compressive tests and ultrasonic techniques, Cement and Concrete Research $36(5)(2006) 858-867$.

[14] T. Chotard, N. Gimet-Brert, A.Smith, D. Fargeto. J. P. Bonnet, C. Gault, Application of ultrasonic testing to describe the hydration of calcium aluminate cement at the early age, Cement and Concrete Research 31 (3) (2001) 405-412.

[15] H. K. Lee, K. M. Lee, Y. H. Kim, H. Yim, D. B. Bae, Ultrasonic in-situ monitoring of setting process of high-performance concrete, Cement and Concrete Research 34 (4) (2004) 631-640.

[16] J. R. Rapoport, J. S. Popovics, V. K. Subramaniam, S. P. Shah, Using ultrasound to monitor stiffening process of concrete with admixtures, ACI Mater. J. 97 (2000) 675-683.

[17] J. Keating, D. J. Hannant, A. P. Hibbert, Comparison of shear modulus and pulse velocity techniques to measure the build-up of structure in fresh cement pastes used in oil well cementing, Cement and Concrete Research 19 (4) (1989) 554-566.

[18] C. M Sayers, R. L. Grenfell, Ultrasonic propagation through hydrating cements, Ultrasonics 31, (3) (1993) 147-153.

[19] P. C. Hewlett, Lea's Chemistry of Cement and Concrete, Elsevier, Burlington MA, 2004. 
Table 1

Characteristics of cements

\begin{tabular}{llllllll}
\hline cement type & label & $\mathrm{AC}[\%]$ & $\mathrm{BS}\left[\mathrm{cm}^{2} / \mathrm{g}\right]$ & $\mathrm{C}_{3} \mathrm{~S}[\%]$ & $\mathrm{C}_{2} \mathrm{~S}[\%]$ & $\mathrm{C}_{3} \mathrm{~A}[\%]$ & $\mathrm{C}_{4} \mathrm{AF}[\%]$ \\
\hline CEM II/A-S, 42.5R & $\mathrm{C} 1$ & $>80$ & 4260 & 32.85 & 46.32 & 10.36 & 10.47 \\
CEM I, 52.5 R & $\mathrm{C} 2$ & $>95$ & 4310 & 57.70 & 13.00 & 6.90 & 8.90 \\
CEM I, 42.5 N & $\mathrm{C} 3$ & $>95$ & 2640 & 60.20 & 13.60 & 7.20 & 9.30 \\
CEM I, 42.5 N SR & $\mathrm{C} 4$ & $>95$ & 3130 & 55.90 & 21.90 & 2.30 & 15.00 \\
\hline
\end{tabular}


Table 2

Cement paste mixtures

\begin{tabular}{llllll}
\hline Mixture & Cement & $\mathrm{T}\left[{ }^{\circ} \mathrm{C}\right]$ & w/c & BS $\left[\mathrm{cm}^{2} / \mathrm{g}\right]$ & $\mathrm{C}_{3} \mathrm{~A}[\%]$ \\
\hline MC1035 & $\mathrm{C} 1$ & 21 & 0.35 & 4260 & 10.36 \\
MC1040 & $\mathrm{C} 1$ & 21 & 0.40 & 4260 & 10.36 \\
MC1050 (REF), MT1 & $\mathrm{C} 1$ & 21 & 0.50 & 4260 & 10.36 \\
MT2 & $\mathrm{C} 1$ & 26 & 0.50 & 4260 & 10.36 \\
MT3 & $\mathrm{C} 1$ & 32 & 0.50 & 4260 & 10.36 \\
MC2, MF1 & $\mathrm{C} 2$ & 21 & 0.50 & 4310 & 6.90 \\
MC3, MF2, MC3A1 & $\mathrm{C} 3$ & 21 & 0.50 & 2640 & 7.20 \\
MC4, MC3A2 & $\mathrm{C} 4$ & 21 & 0.50 & 3130 & 2.30 \\
MF3 & $\mathrm{C} 2, \mathrm{C} 3$ & 21 & 0.50 & 3490 & 7.10 \\
MC3A3 & $\mathrm{C} 3, \mathrm{C} 4$ & 21 & 0.50 & 2805 & 4.80 \\
\hline MC2040 & $\mathrm{C} 2$ & 21 & 0.4 & 4310 & 6.90 \\
MC3040 & $\mathrm{C} 3$ & 21 & 0.4 & 2640 & 7.20 \\
\hline
\end{tabular}


Table 3

Initial setting time data for all cement paste mixtures

\begin{tabular}{llllllll}
\hline \multirow{2}{*}{$\begin{array}{l}\text { Mixture } \\
\text { label }\end{array}$} & \multicolumn{3}{c}{ characteristic points [hours] } & \multicolumn{3}{c}{ Value of $V p[\mathrm{~m} / \mathrm{s}]$} \\
\hline MC1035 & 43 & $t 9$ & $t_{I P 1}$ & $t_{w}$ & $V p_{3}$ & $V p_{9}$ & $V p_{I P 1}$ \\
MC1040 & 5.5 & 4.7 & 4.3 & 4.2 & 1510 & 1520 & 1490 \\
MC1050, MT1 & 6.3 & 5.5 & 5.3 & 5.4 & 1420 & 1435 & 1420 \\
MT2 & 5.9 & 7.3 & 7.2 & 7.2 & 1390 & 1450 & 1430 \\
MT3 & 4.7 & 5.8 & 5.8 & 6.0 & 1320 & 1350 & 1320 \\
MC2, MF1 & 4.3 & 5.3 & 5.1 & 5.4 & 1280 & 1390 & 1350 \\
MC3, MF2, MC3A1 & 6.5 & 6.9 & 6.7 & 6.3 & 1498 & 1550 & 1520 \\
MC4, MC3A2 & 7.8 & 8.0 & 7.7 & 8.1 & 1380 & 1410 & 1370 \\
MF3 & 4.9 & 5.2 & 4.9 & 5.1 & 1400 & 1450 & 1400 \\
MC3A3 & 7.2 & 7.5 & 7.1 & 7.4 & 1380 & 1440 & 1370 \\
MC2040 & 3.0 & 3.4 & 3.2 & 3.3 & 1350 & 1480 & 1410 \\
MC3040 & 5.4 & 5.8 & 5.4 & 5.4 & 1440 & 1480 & 1440 \\
\hline
\end{tabular}


a)

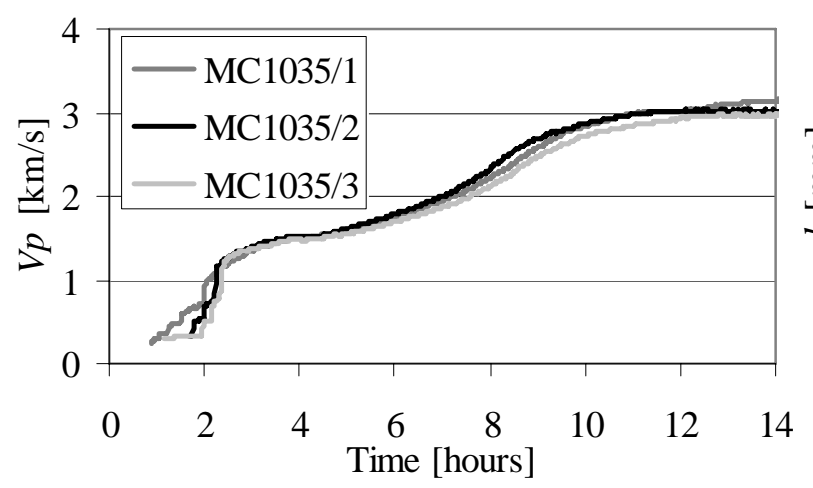

b)

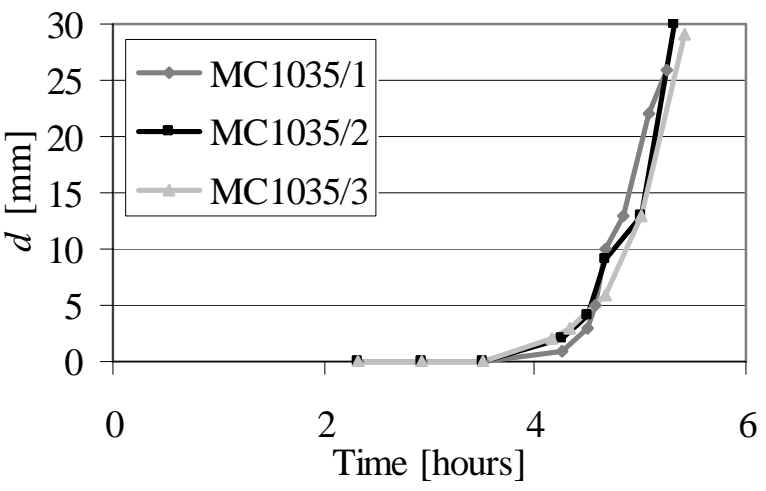

Fig. 1. Reproducibility of the methods. a) Ultrasonic wave transmission method - UPV curves, b) Vicat Needle method - VNM curves. 
a)

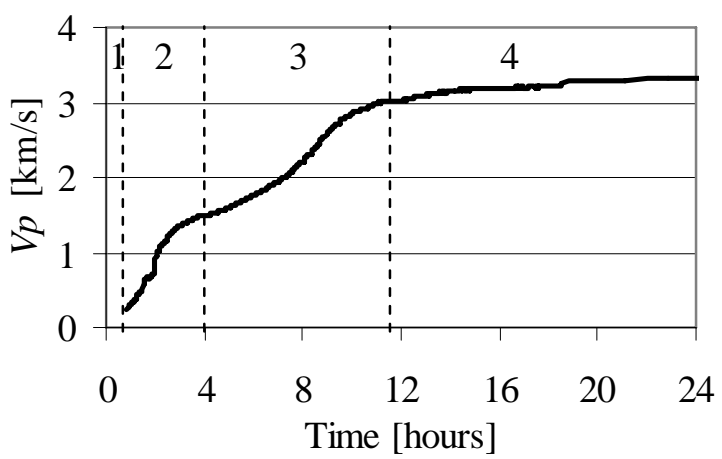

b)

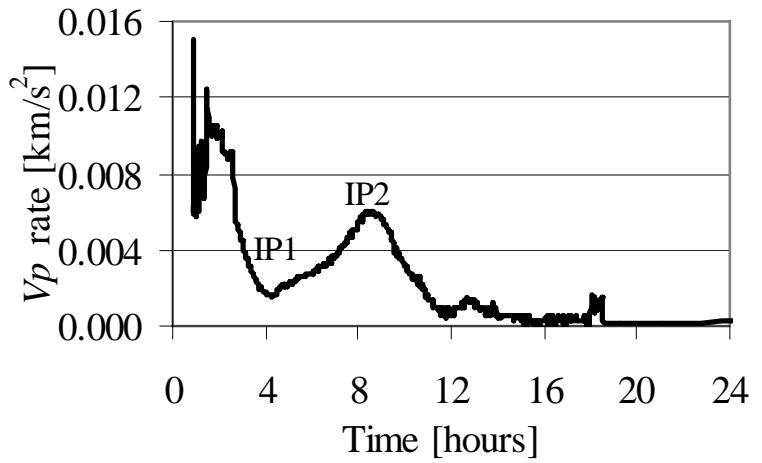

Fig. 2. Typical UPV curve for the cement paste. a) Evolution of the $V p$, b) rate of the Vp evolution. 
a)

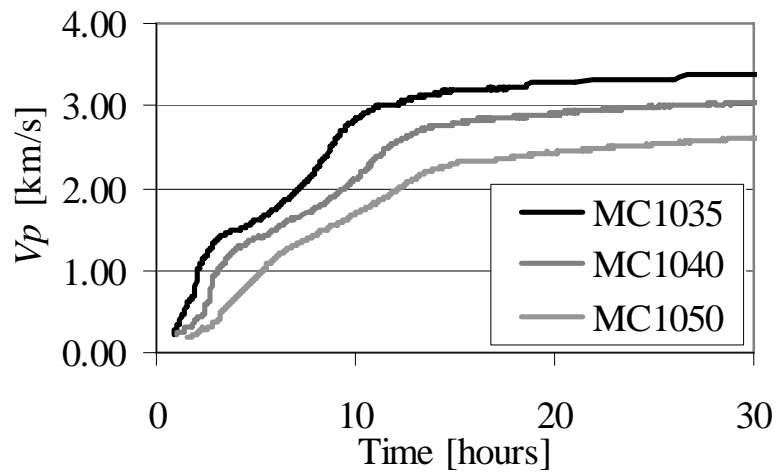

c)

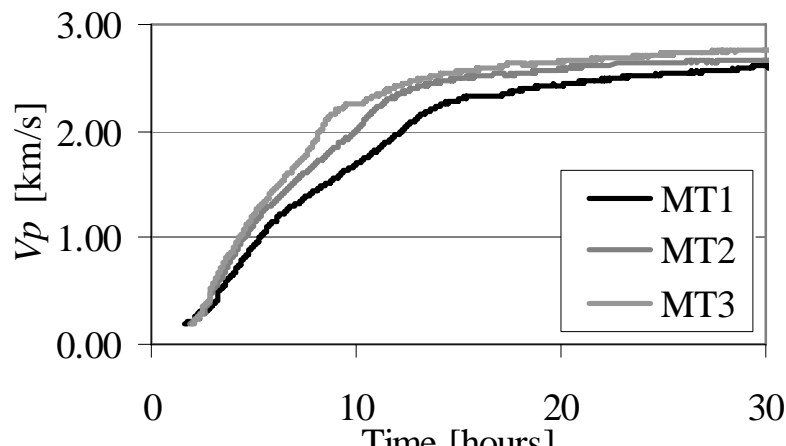

e)

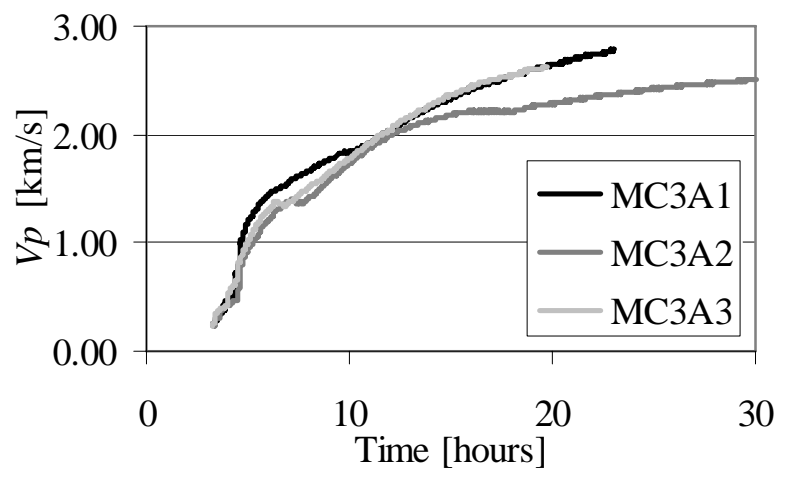

b)

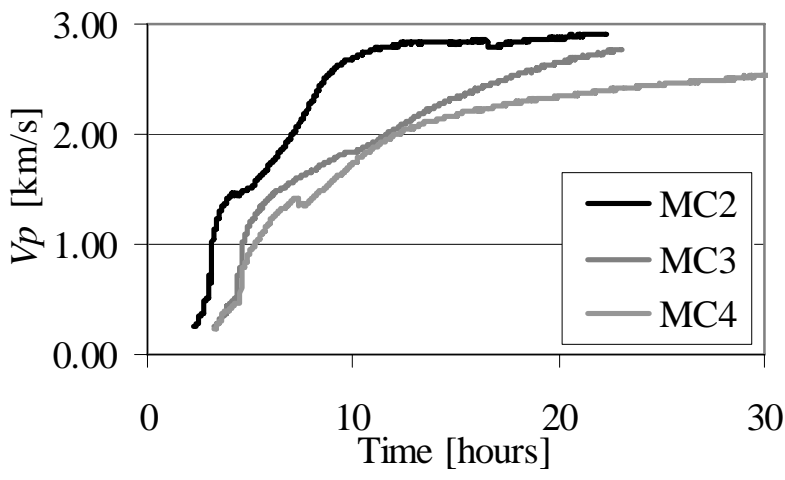

d)

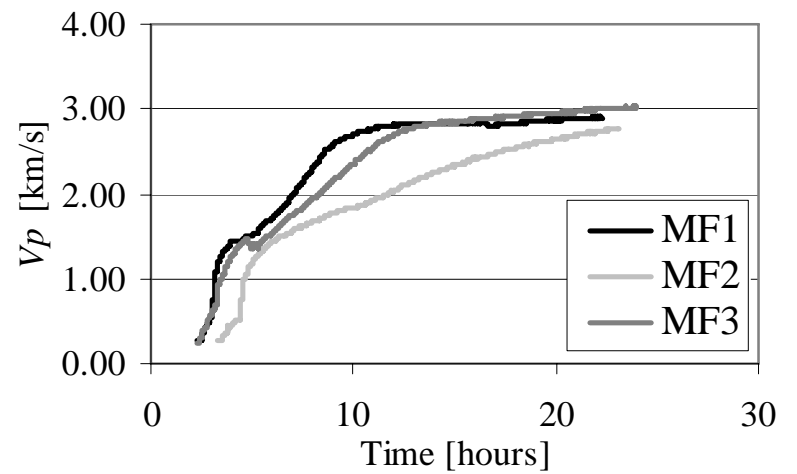

Fig. 3. The influence of the discussed parameters on the evolution of $V p$. a) The influence of the w/c ratio, b) the influence of cement type, c) the influence of the curing temperature, d) the influence of the cement fineness, e) the influence of the cement composition. 
a)

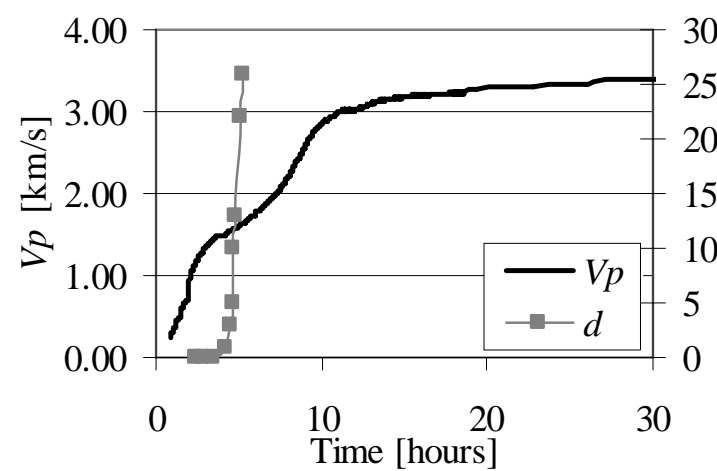

c)

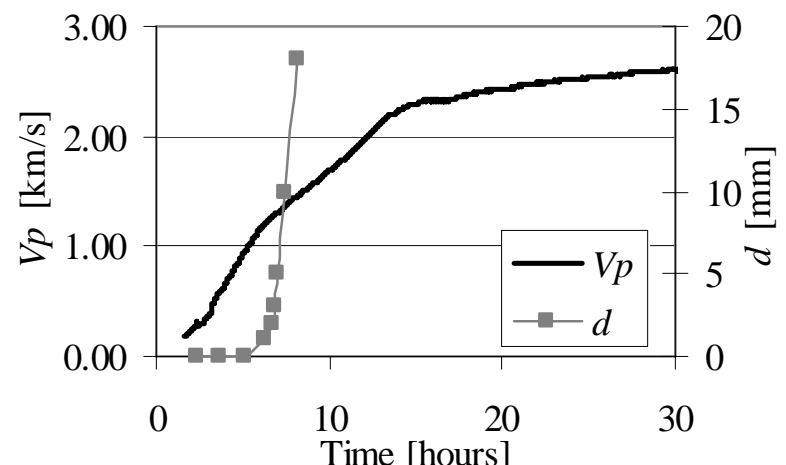

e)

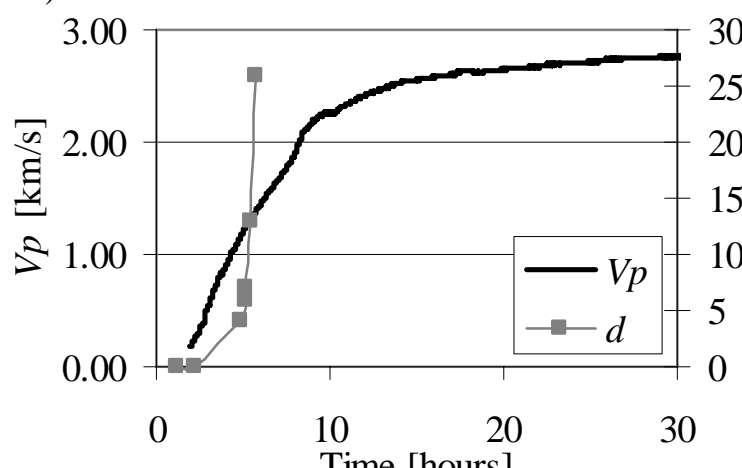

g)

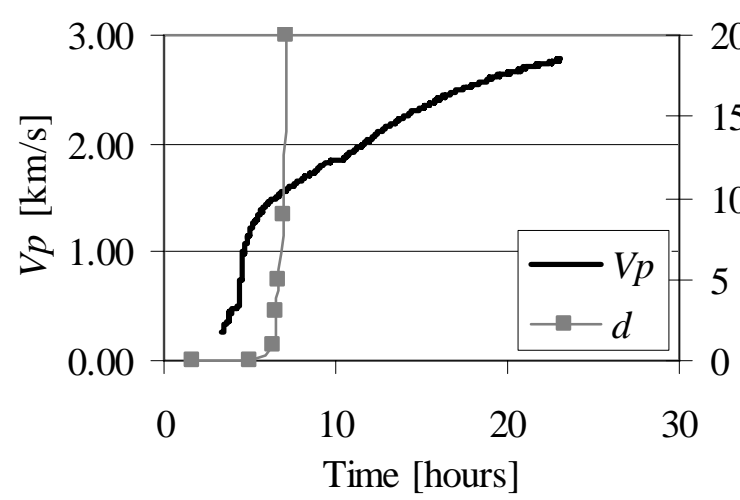

b)

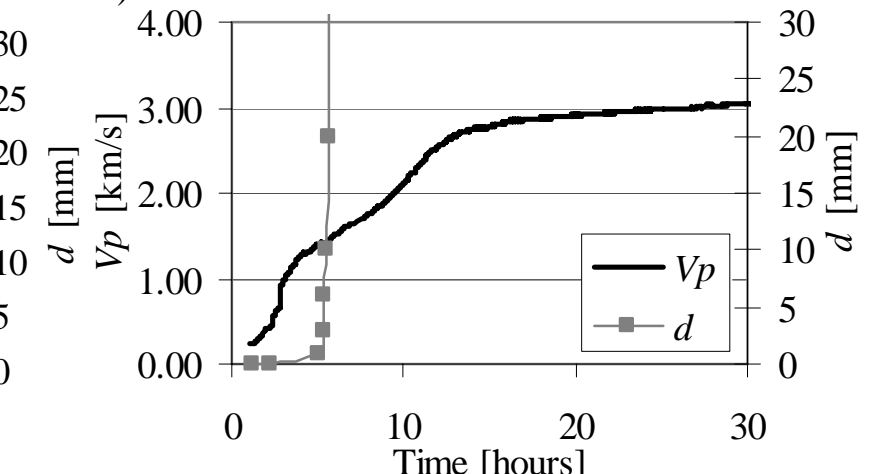

d)

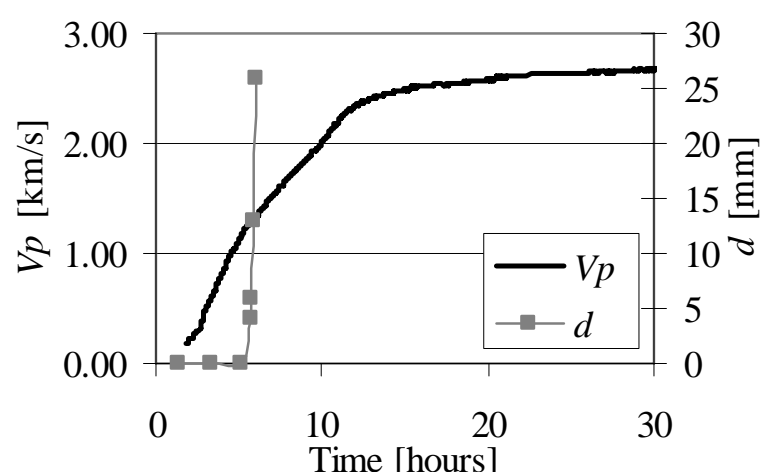

f)

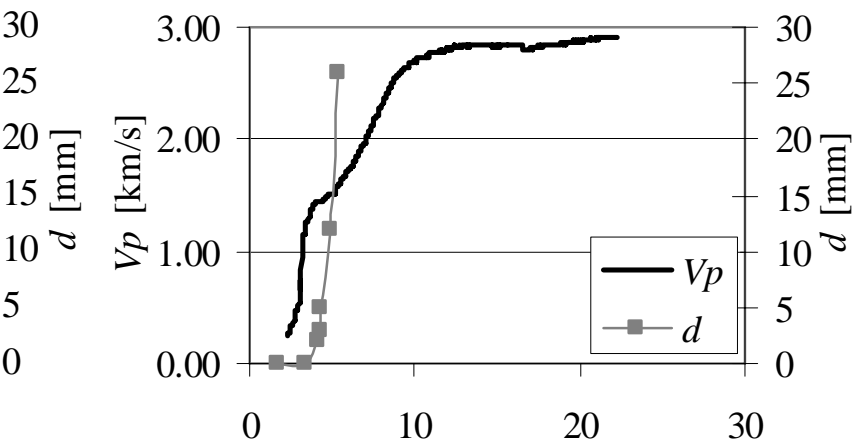

h)

Time [hours]

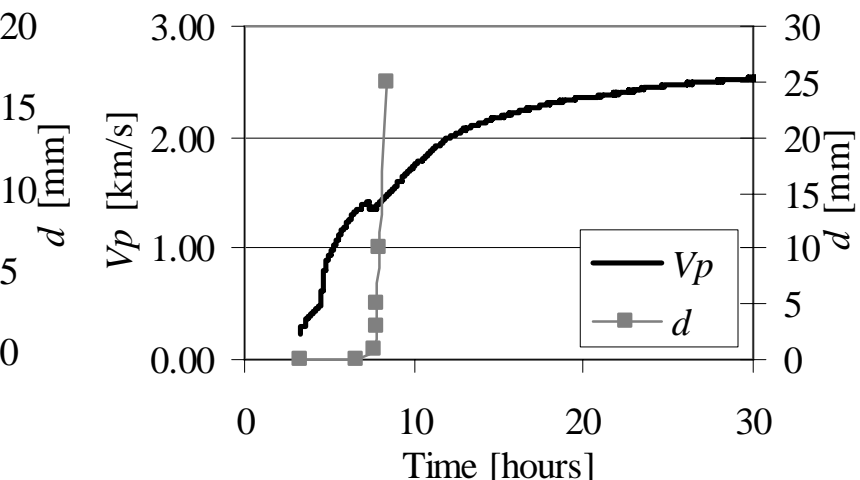


i)

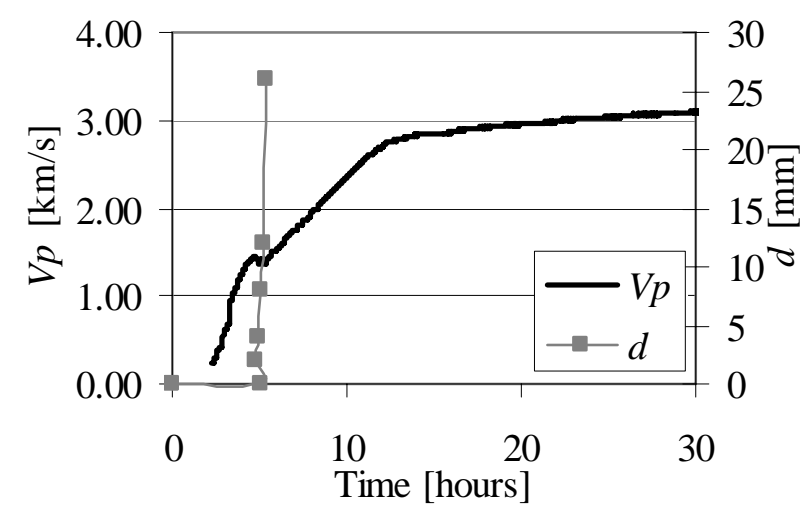

k)

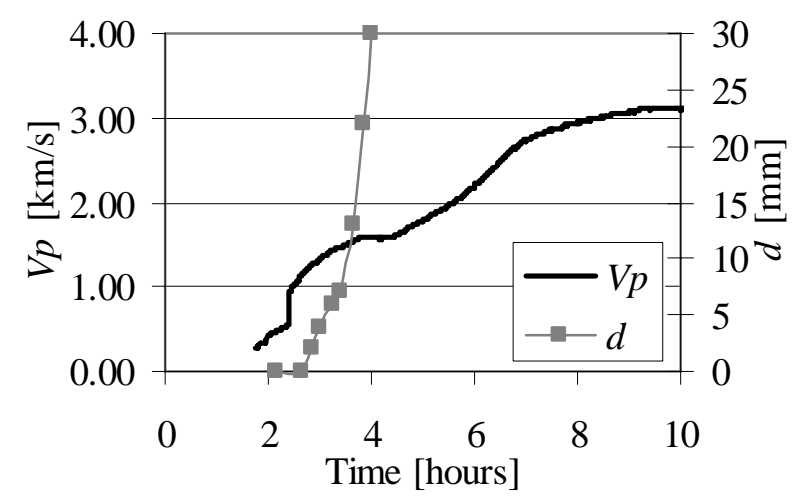

j)

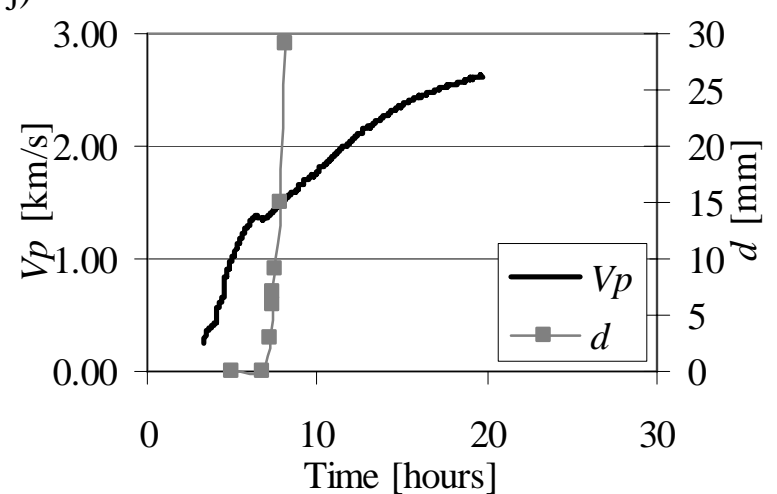

1)

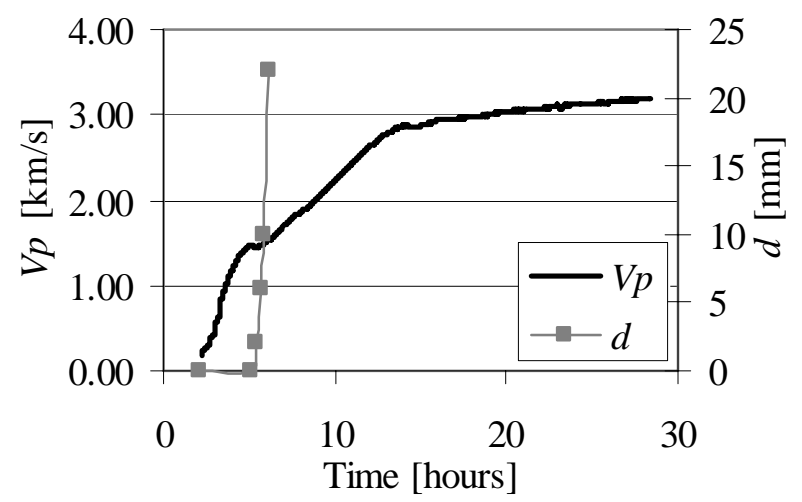

Fig. 4. The relationship between $V p$ and $d$ for all cement paste mixtures. a) mixture MC1035, b) mixture MC1040, c) mixture MC1050, MT1, d) mixture MT2, e) mixture MT3, f) mixture MC2, MF1, g) mixture MC3, MF2, MC3A1, h) mixture MC4, MC3A2, i) mixture MF3, j) mixture MC3A3, k) mixture MC2040, l) mixture MC3040. 
a)

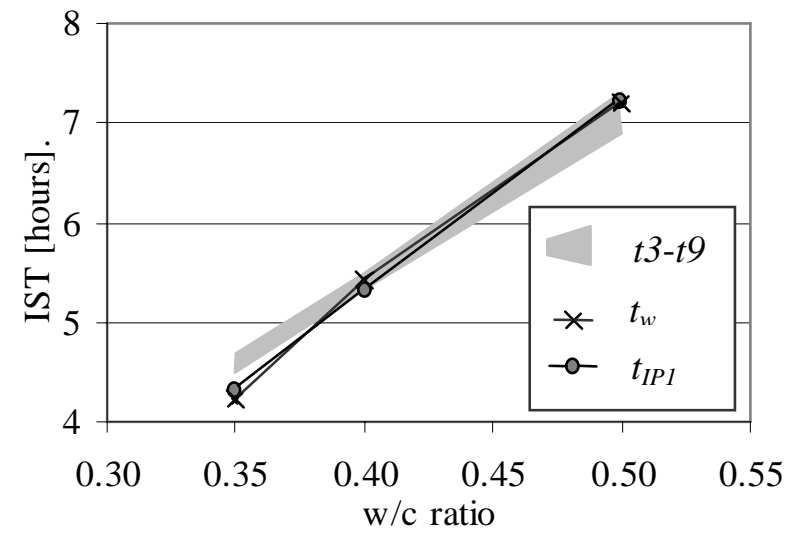

c)

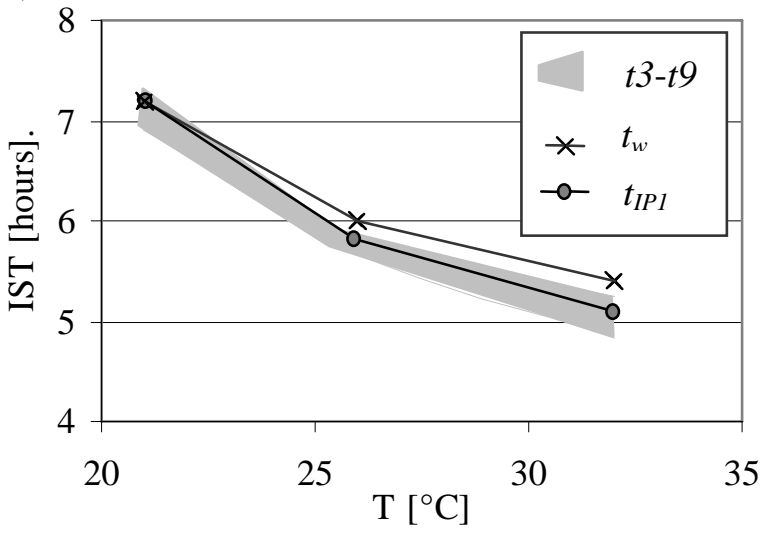

b)

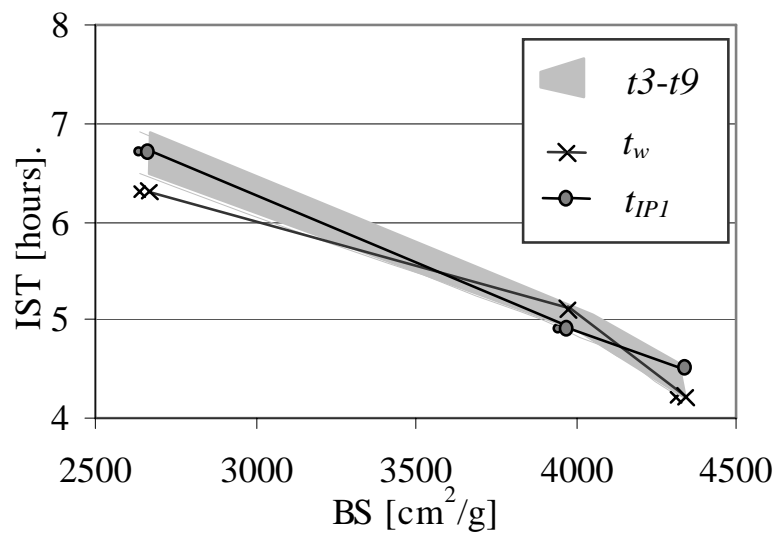

d)

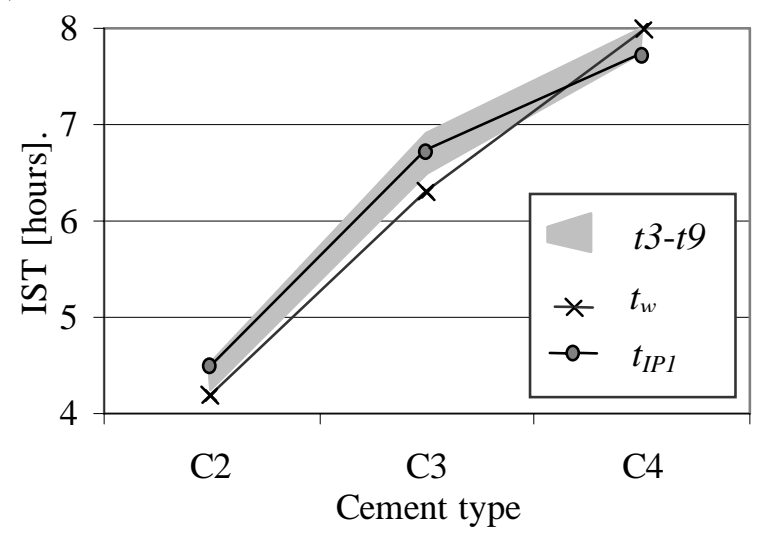

Fig. 5. The influence of some of the discussed parameters on the $t 3-t 9$ interval, $t_{w}$, and $t_{I P 1}$. a) The influence of the w/c ratio, b) the influence of the cement fineness c) the influence of the curing temperature, d) the influence of the cement type. 